\title{
A New Approach for Treatment of Bone Hydatid Cyst Disease: A Case Report of Primer Femur Hydatid Cyst \\ H Çabuk ${ }^{1}$, AÇ Tekin ${ }^{1}$, S Ayanoğlu ${ }^{1}$, CD Büyükkurt ${ }^{1}$, H Gürbüz ${ }^{1}$, FK Çabuk $^{2}$
}

\section{INTRODUCTION}

Hydatidosis is a tapeworm infection caused by the Echinococcus species (1). Involvement of the long tubular bones is rare in hydatid bone disease. Skeletal hydatidoses occurs in $0.5-2 \%$ cases (2). Bone hydatidosis with long bone involvement of the femur (16\%) seen less commonly $(3,4)$. The cysts occasionally lie dormant in the body for up to 20 years without producing clinical signs or symptoms (3).

We report a case of hydatidosis of the femur with pathologic fracture in a 23 -year-old man.

Keywords: femur, hydatid cyst, prosthesis

From: ${ }^{1}$ Department Of Orthopedics and Traumatology, Okmeydanı Training and Research Hospital and ${ }^{2}$ Department of Medical Pathology, İstanbul Bilim University,

Correspondence: Dr Çabuk, Department Of Orthopedics and Traumatology, Okmeydanı Training and Research Hospital. E-mail: halukcabuk@ hotmail.com 


\section{CASE REPORT}

A 23-year-old man presented to Emergency Department with a low energy femur fracture. He had fractured his femur while descending the stairs. Routine blood investigations was within normal limits except CRP was elevated $[21.47 \mathrm{mg} / \mathrm{dL}]$ (normal was 0-5 mg/dL).

He has a history of operation from his left femur because of a fracture and a sliding hip plate was applied 10 years ago.

Radiographs of left femur revealed a multiloculated osteolytic lesions and subtrochanteric communucated fracture.with a sliding plate (Fig. 1).

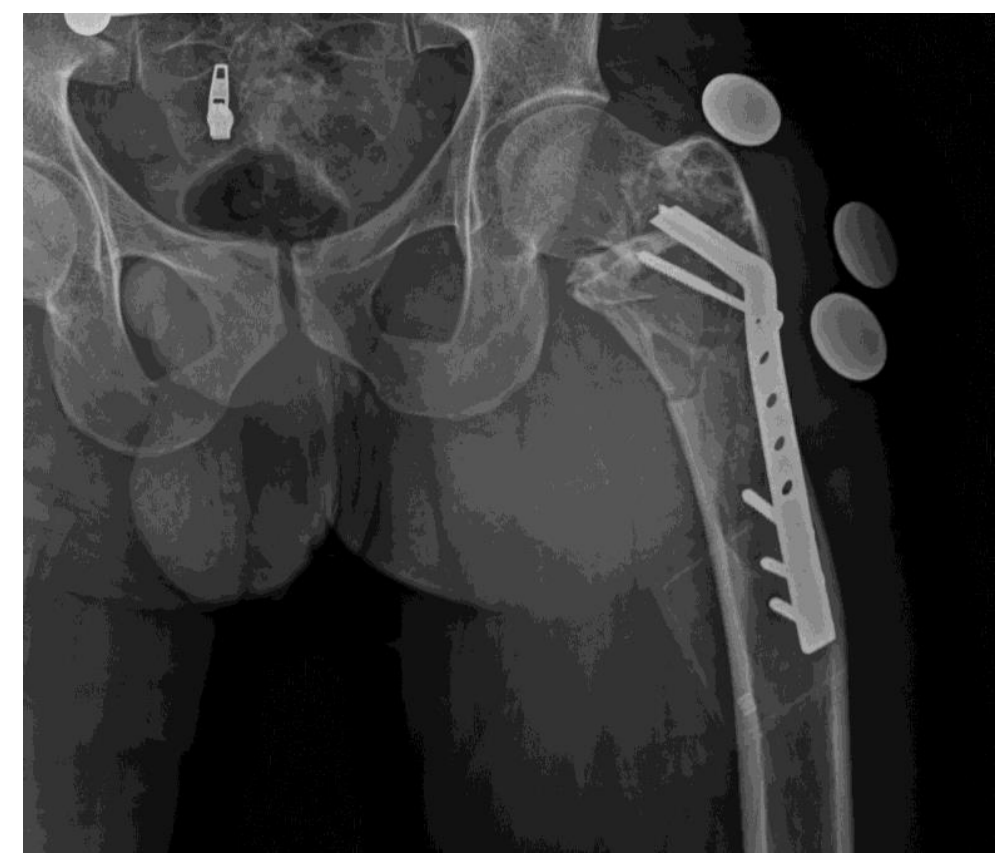

Fig: 1. Multiloculated osteolytic lesions and subtrochanteric communucated fracture.

Computerized tomography (CT) show a multiloculated cystic lesion with cortical expansion and thinning of the cortices, extending from collum of femur to subtrochanteric region (Fig. 2). A low grade infection or malignancy was made for intial dignosis. 


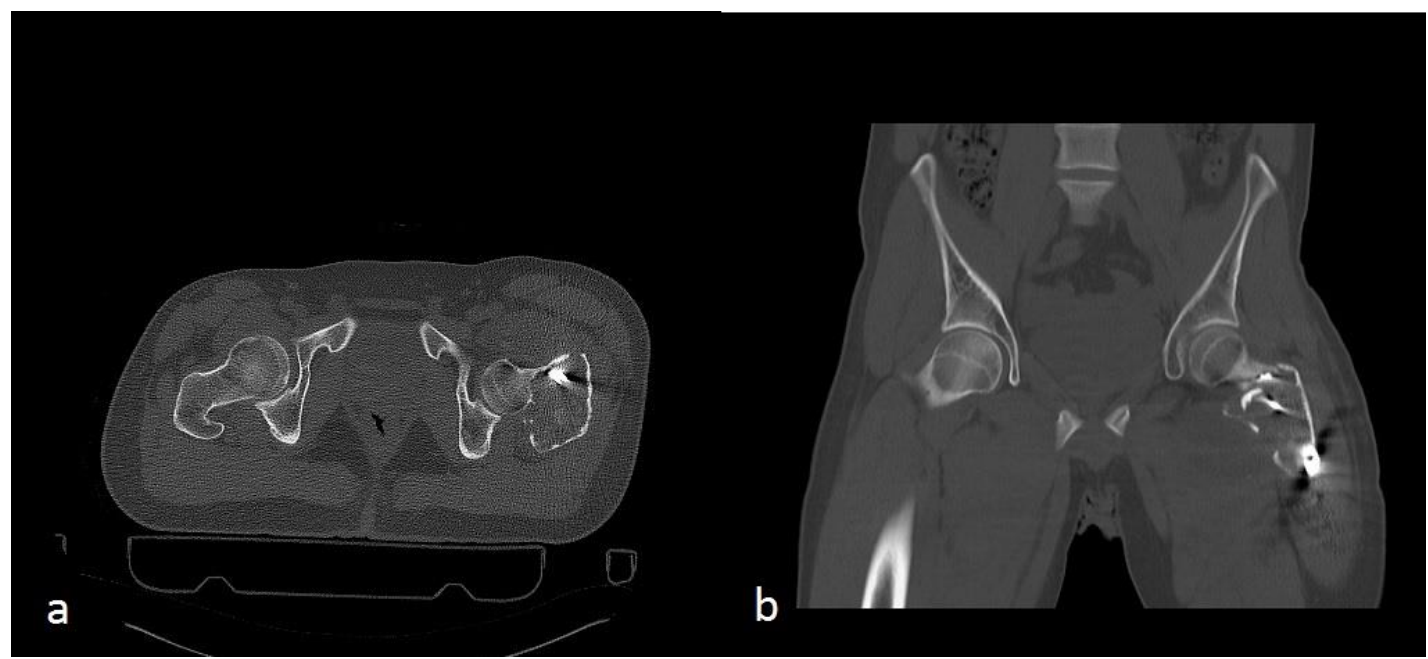

Fig: 2. Axial and coronal sections of tomography of patients.

The patient was operated to for hardware removal and obtaining bone biopsy from the fracture side. In surgical gross anatomy cystic vesicules were seen in the fracture side. Histopathological examination revealed laminated hyaline membrane compatible with the diagnosis of hydatid cyst (Figs. 3, 4).

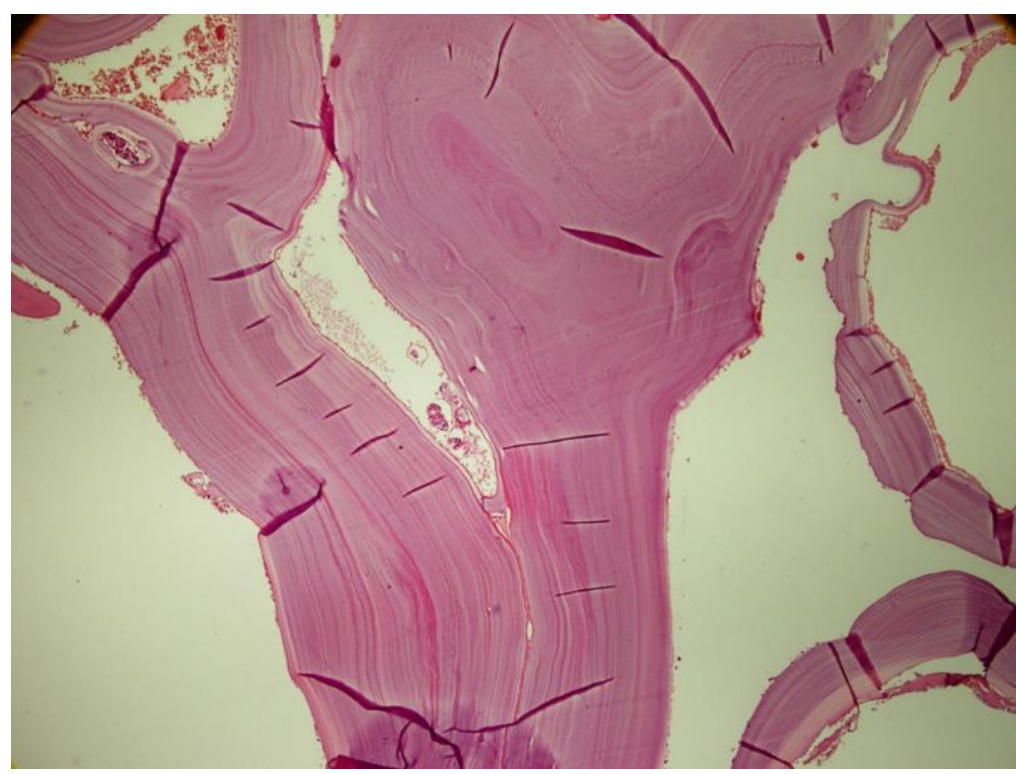

Fig: 3. Histologic examination of the cyst wall shows an outer chitinous layer and an inner germinal layer which contains daughter cysts and brood capsules with scolices (Hematoxylin\&Eosin x 40). 


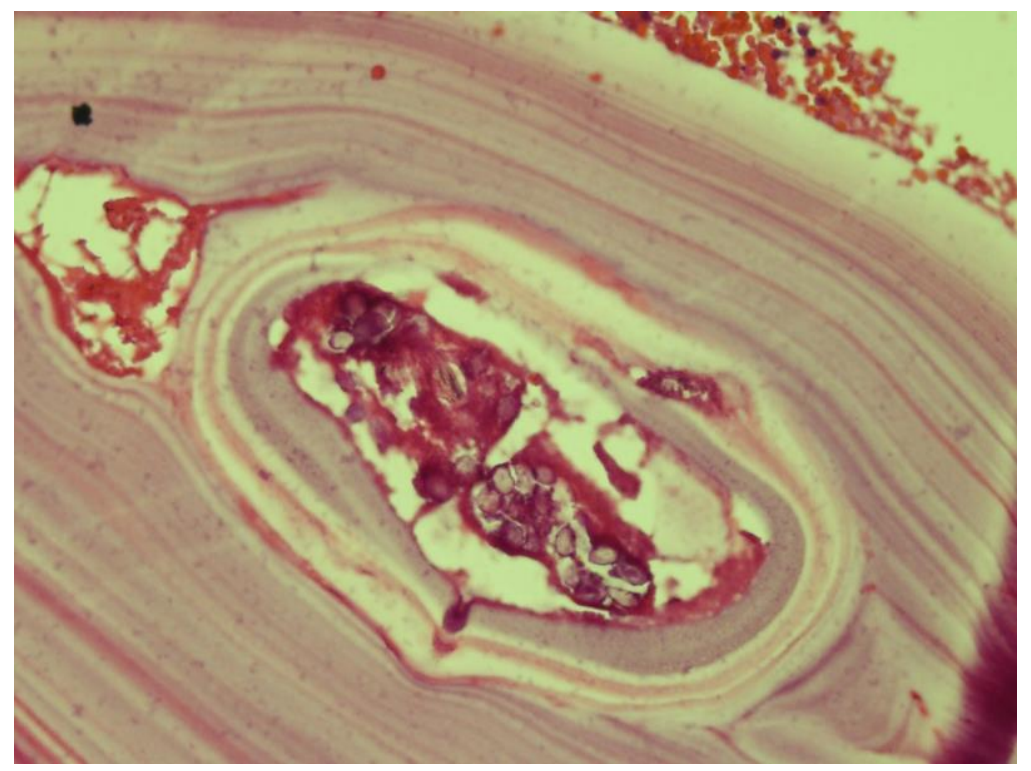

Fig: 4. This is high magnification, daughter cyst which contains scoleces are found in the chitinous layer of the cyst (H\&E x 400).

Blood test confirmed the hydatid cyst disease. An indirect hemiaglutinin test for echinococcal antibody was positive (1/1280) after the histopathological diagnosis was made.

After histopathological diagnosis was made magnetic resonance imaging was made and proximal 2/3 of entire femur was filled with hydatic cysts (Fig. 5).

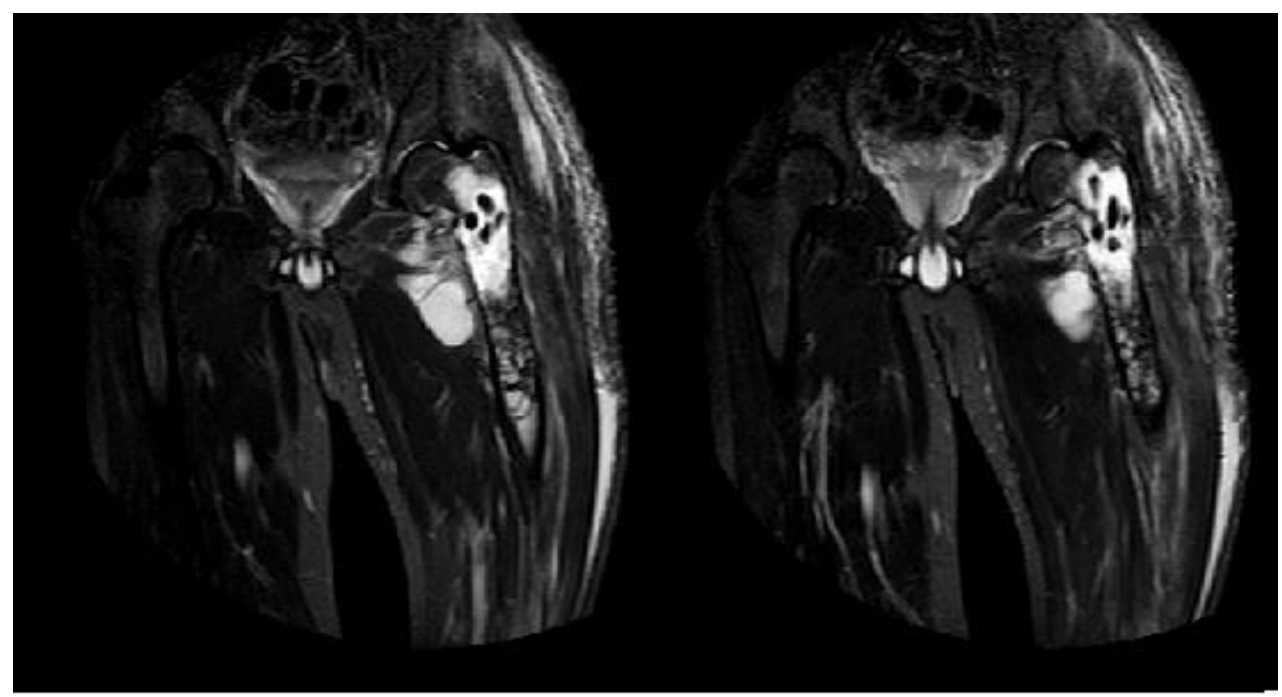

Fig: 5. Continuos MRI sections of the patients left femur demostrating the widespread lesions of cyst hydatic. 
Contamitaion of cysts are also seen between adductor muscles and vastus intermedius muscle. Because cyst hydatidosis mainly seen in liver and lungs, abdominal, thoracal and cranial CT are obtained and no abnormalities is seen.

Preoperative planning was made and tumour resection prothesis implantation desicion made. Because hypertonic solution were routine used in abdominal hydatidosis we also decide to use hypertonic saline solution. Patient operated and effected segments of femur $(25 \mathrm{~cm}$ in length) removed and muscle planes are irrigated with hypertonic saline solution and a tumour resection prothesis (Mutars Total Femur Replacement Systems, İmplantcast, Germany) is applied. Because of contamination of muscle mass a continious negative pressure and irrigation wound closure system (VAC Instill ${ }^{\circledR}$ Therapy Unit, US) is used with irrigation solution of hypertonic saline for two weeks. After two weeks wound is closed in usual manner. A rehabilation programme started and patient mobilized with crutches after two week.

The patients were administered postoperative chemotherapy with albendazole $(10 \mathrm{mg} / \mathrm{kg} /$ day) for six months with close observation of the liver enzymes.

At the 12-month follow-up, patient is moblized with only a cane and we detected no findings associated with local or systemic hydatid cyst. Radiological images taken after first year showed no recurrence and serological tests remained negative (Fig. 6). 


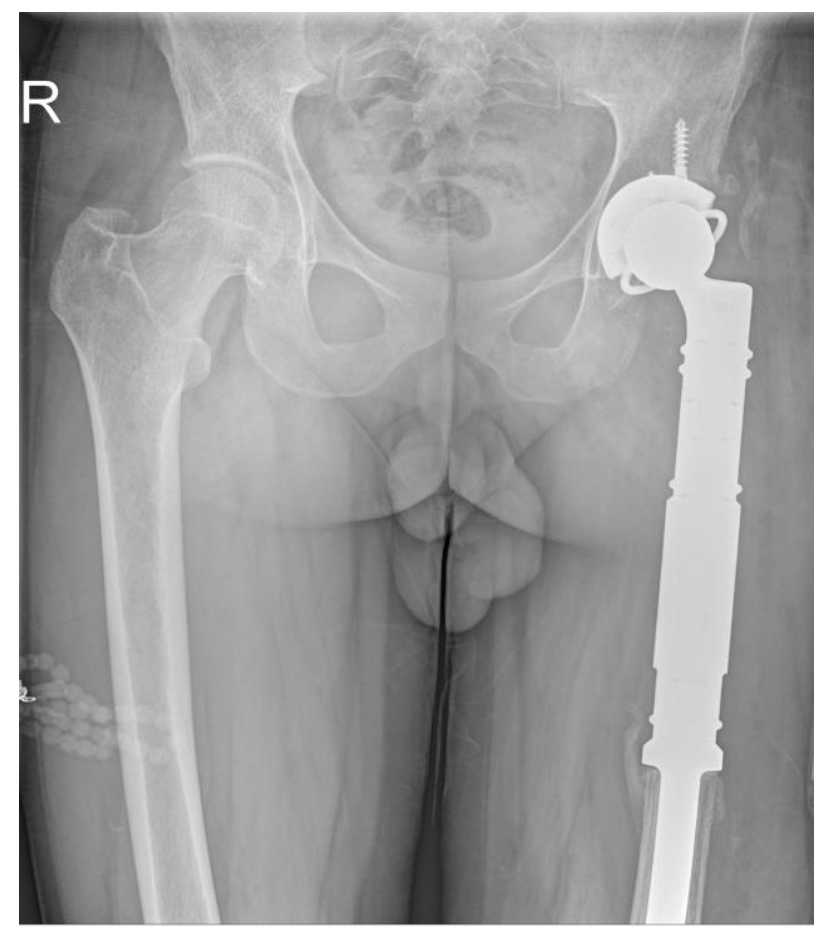

Fig: 6. Radiological images taken after first year showed no recurrence

\section{DISCUSSION}

Echinococcosis, which is known as unilocular hydatid disease or human hydatid disease is caused by the larvae of E Granulosus. Bone hydatidosis commonly involves the spine and pelvis. Hydatid involvement of long tubular bones, especially the femur diaphysis, is rare $(5,6)$ The disease initially involves the epimetaphyseal region, often extending to the diaphyseal region at presentation (1). Progressive changes and an expanding cystic appearance may mimic tumour formation (7). In our case location was left femur extending from collum femoris to distal diaphysial area. A pathologic fracture had occured before diagnosis in our case. Cystic apperance may be misdiagnosed as tumoural lesions so we perform a biopsy while hardware removal. It is difficult to diagnose bone hydatid cyst disease radiologically because the findings are non-specific (8). Plain radiographic findings in hydatid bone disease include intramedullary unilocular, bilocular and often multiloculated cystic expansile lesions with surrounding sclerosis in a honeycomb pattern associated with cortical 
thinning (9). A definite diagnosis can only be reached by histopathological evaluation of resected tissues. Tuberculosis simple bone cyst, fibrous dysplasia, malign fibrous hystiosytom, sarcoma and metastasis should be consider in differantial diagnosis (10).

Surgical treatment is usually based on the same principles as described for a locally malignant lesion (1). The best treatment for bone infection originating from echinococcosis is removal of the involved bone or amputation (7). However, curettage and lavage with hypertonic salt, $1 \%$ formalin, or $0.5 \%$ silver nitrate solutions have been attempted (7).

Although wide excision of the infected bone provides the best chance of cure, it usually leaves an extensive bone defect that can produce a challenge during reconstruction (11). In our case we resected $2 / 3$ of the femur and reconstruction of that was impossible.

Although amputation was one of the treatment alternatives, both using a tumour resection prosthesis with a continues irrigation with hypertonic saline solution gives us a change to save the limb. Recurrence of the disease can complicate prosthetic reconstruction after cyst excision (12). The current literature includes reports of patients whose hip was treated with total hip replacement. Two of these patients died due to complications; both died four years after surgery after chronic sepsis $(2,13)$. Neelapala et al, perform a revision hip replacement for a cyst hydatic but in his case extension of disease was through to ilium. Our case is the first case in litreture that treatment with a tumour resection prothesis with a continous irrigation with hypertonic solution.

As a conlusion hydatid disease involving the long tubular bones should initially be treated as a low-grade malignant neoplasm. In extensive lesions of bone and soft-tissue a tumour resection prosthesis with a continuos hypertonic saline irrigation can be an alternative treatment for amputation of the effected limb. 


\section{REFERENCES}

1. Zlitni M, Ezzaouia K, Lebib H, Karray M, Kooli M, Mestiri M. Hydatid cyst of bone: diagnosis and treatment. World J Surg 2001; 25: 75-82.

2. Sapkas GS, Stathakopoulos DP, Babis GC, Tsarouchas JK. Hydatid disease of bones and joints. 8 cases followed for 4-16 years. Acta Orthop Scand 1998; 69: 89-94.

3. Morris BS, Madiwale CV, Garg A, Chavhan GB. Hydatid disease of bone: a mimic of other skeletal pathologies. Australas Radiol 2002; 46: 431-4.

4. Gossios KJ, Kontoyiannis DS, Dascalogiannaki M, Gourtsoyiannis NC. Uncommon locations of hydatid disease: CT appearances. Eur Radiol 1997; 7: 1303-8.

5. Herrera A, Martinez AA. Extraspinal bone hydatidosis. J Bone Joint Surg Am. 2003; 85-A:1790-4.

6. Merkle EM, Kramme E, Vogel J, Kramer S, Schulte M, Usadel S et al. Bone and soft tissue manifestations of alveolar echinococcosis. Skeletal Radiol 1997; 26: 289-92.

7. Canale ST, Beaty, J.H. Campbells Operative Orthopaedics. İstanbul: Güneş medical book house; 2011.

8. Polat P, Kantarci M, Alper F, Suma S, Koruyucu MB, Okur A. Hydatid disease from head to toe. Radiographics 2003; 23: 475--94; quiz 536-7.

9. Song XH, Ding LW, Wen H. Bone hydatid disease. Postgrad Med J 2007; 83: 536-42.

10. Ekinci Y, Duygulu F, Vatansever F, Gurbuz K. A giant hydatid cyst localized in pelvis and thigh. E Eklem Hastalik Cerrahisi 2014; 25: 121-4.

11. Gdoura F, Trigui M, Zribi W, Ellouze Z, Bouzidi R, Ayedi K et al. Pelvic bone hydatidosis. Orthop Traumatol Surg Res 2010; 96: 85-9. 
12. Neelapala VS, Chandrasekar CR, Grimer RJ. Revision hip replacement for recurrent Hydatid disease of the pelvis: a case report and review of the literature. J Orthop Surg Res 2010; 5: 17.

13. Voutsinas S, Sayakos J, Smyrnis P. Echinococcus infestation complicating total hip replacement. A case report. J Bone Joint Surg Am 1987; 69: 1456-8. 